and a table of goniometrical functions for the four quadrants, compiled by Profs. J. C. and W. Kapteyn ; additional formulæ, both for plane and spherical triangles where certain elements are small, are also included.

The Leeds Astronomical Society.-We have just received No. ${ }^{3} 3$ of the Journal and Transactions of the Leeds Astronomical Society, which gives a brief résume of the work accomplished by the members of the society during the year 1905 .

Eight papers read before the society during the session, dealing with popular astronomical subjects, are reproduced in the journal, together with a number of notes contributed by members to various publications.

From remarks made in the report it appears that this society is greatly in need of increased support, financial and general.

\section{METEOROLOGICAL OBSERVATIONS.}

If ROM the "Jahrbücher" of the Austrian Meteorologica Office for IgO4 it appears that changes have recently been made in the comprehensive operations of that important institution. A considerable addition to its labours has been incurred by the transfer to it of the observations of earthquake phenomena originated by the Vienna Academy of Sciences; this organisation embraces a large number of stations. Owing to this transfer the office has adopted the title of Central-Anstalt für Meteorologie und Geodynamik. A considerable increase has been made in the number of weather forecasts sent gratuitously to provincial postoffices; in these telegrams an attempt is made to forecast the weather for two days in advance. On the other hand, it has been found necessary greatly to restrict the amount of data published from stations of the second and third order; this materially lessens the bulk of the year-book. The investigation of the upper air by manned and unmanned balloons is actively continued, and the results are published in the Proceedings of the academy. A separate appendix contains a revision of the yearly means of barometric pressure at various stations since 1886 , by $\mathrm{Dr}$. Margueles, and a discussion of thunderstorms and hail, by M. Prohaska.

The results of meteorological and magnetical observations at Stonyhurst College for 1905 have just been issued. This useful observatory possesses photographic recording instruments both for meteorology and terrestrial magnetism, and was one of the seven principal stations included in the scheme of the Meteorological Committee in I 868 for the discussion of the meteorology of the British Isles; its observations extend over the long period of fiftyeight years. The most notable feature of the year appears to us to be the shortage of rainfall, amounting to just upon 8 inches. The total rainfall was 38.84 inches; the least fall in any year was $3 \mathbf{I} \cdot 25$ inches, in 1887 . The prevailing wind was between south and west on 237 days. Drawings of solar spots and faculæe were made on 196 days, and the stellar spectrograph was employed on nearly every available night.

The fourteenth report of the Sonnblick Society for the year 1905 contains statistics of several prominent mountain meteorological stations, including an interesting account of the observatory at the summit of Monte Rosa, at an altitude of about 14,960 feet. The Sonnblick station (Salzburg) is about ro, rgo feet above the sea-level, and is far from an agreeable residence for its enthusiastic observers. The mean temperature for the year 1905 was $19^{\circ} .9 \mathrm{~F}$. ; the monthly mean was only above freezing point in July and August, the absolute maxima in those months being $56^{\circ} .8$ and $45^{\circ} .7$ respectively. Rain or snow fell on 230 days, amounting to 68.8 inches, and fog occurred on 274 days. On January $\mathrm{I}$ the thermometer fell to $-35^{\circ} \cdot 3$ being the lowest observed since the establishment of the observatory, the next lowest reading being $-30^{\circ} \cdot 3$, in March, I89o; the wind was north-easterly, with high barometric pressure $(30.7 \mathrm{I}$ inches) over Scandinavia and low (29.53 inches) over Greece.

The twenty-eighth yearly report of the Deutsche Seewarte, for the year 1905 , shows a considerable increase in the useful work of that institution; the number of sets of observations contained in ships' logs exceeded those of the previous year by more than 28,000. These observations are utilised in the publication of monthly charts for the North Atlantic, quarterly charts for the North Sea and Baltic, the preparation of valuable daily synoptic weather charts of the, North Atlantic (in conjunction with the Danish Meteorological Institute), and various other investigations. Special mention may be made of the efficiency of the arrangements for the issue of weather forecasts and storm warnings, and of the careful discussion and publication of the observations made at distant stations, including Labrador, the South Seas, the Far East, and German East Africa. The exploration of the upper air by means of kites is actively carried on ; 233 ascents were made during the year, the mean of the greatest altitudes being 3910 metres. It has been found necessary to limit the altitudes, except on the days of the international ascents, owing to the frequent loss of the kites; the principal kite (which carries the instruments) broke away on twenty-two occasions, three of which were due to lightning. Unmanned balloons also reached altitudes of 9 to $x_{7}$ kilometres; the usual inversion of temperature generally occurred between 9 and II kilometres. A discussion of the results obtained will be published later on.

The annual summary of the India Weather Review for 1904, which completes the discussion of the meteorology of India for that year, was issued recently. This vast area is, as before, divided into eleven provinces and fifty-seven districts for the purpose of dealing with medical and agricultural statistics respectively. In addition to various tables giving the usual monthly and other values, each element is separately considered under seasons, including the hot, cold, and monsoon periods. We can here only briefly refer to some of the general annual results. The year was characterised by smaller departures from the normal temperature than is frequently the case; the mean of the maxima for the eleven meteorological provinces was $88^{\circ} .0$, of the minima $68^{\circ} \cdot 7$, and the mean daily range $19^{\circ} \cdot 4$. The Arabian Sea was singularly free from storms; only eleven occurred, and they were all comparatively feeble, and their tracks were less westerly than usual. The rainfall stations now number 2486 ; the mean amount of rainfall was 57.26 inches, about $\mathrm{I}_{2} \frac{1}{2}$ inches below the normal. On the Burma coast the fall was $\mathbf{r}_{52} .65$ inches, and in the Indus valley only $7 \cdot 26$ inches. During the year there was a marked increase in the number of sun-spots; the surface of the sun was not free from them on any day. Magnetic disturbances were recorded at Colába on 205 days, but there were only three days on which they were classed as "great."

The report of the Government Observatory, Bombay, for the year 1905 also quotes a remarkable deficit in the rainfall, it being stated as $4 \mathrm{I} \cdot 5$ inches below the normal of twenty-four years, $1873-1896$. The total fall for the year was 33.66 inches only, and the amount for the previous year was 33.42 inches, both of which are record minimum falls, not even excepting that for the famine year, 1899 , when 35.9 inches were registered. Milne's seismograph recorded thirty-seven earthquakes during 1905 ; those on April 4 and 9 and July 23 were very great disturbances. Plague in a severe epidemic form broke out at Alibág, but no cases occurred in the immediate vicinity of the branch magnetic observatory at that place; one case occurred at Colába in the month of April, notwithstanding that all precautions were taken.

The annual report of the Meteorological Department of the Transvaal for the year ended June 30, 1905, was rereived a few days ago. The central observatory, near Johannesburg, was first occupied in May, I004, and is situated on an abrupt ridge of hills, nearly 6000 feet above sea-level. The department has been very active in supplying verified instruments. and has already some 250 stations in different parts of the colony, the majority of which record rainfall only; the observers are mostly volunteers, and receive no remuneration. The report, however, contains complete meteorological observations, or monthly results, for a considerable number of places, and very useful maps exhibiting the climatological features of the vear in various districts. The diurnal periodicity of rainfall. so far as given. shows that the greater part occurs between noon and midnight. Nearly every fall of rain is 
said to be accompanied with thunder and lightning; some of the storms are very heavy, and a lightning recorder has been erected at Johannesburg which gives a permanent record of their intensity and duration. On the High Veldt the mean temperature of the twelve months ranged from $57^{\circ}$ at Volksrust to $65^{\circ}$ in the Waterberg, the extreme maxima from $87^{\circ}$ to $104^{\circ}$, and the extreme minima from $14^{\circ}$ to $29^{\circ}$. Telegraphic messages are received and exchanged daily, and the Government has sanctioned the appointment of an assistant, to be trained in weather forecasting at the Meteorological Office in London.

\section{THE THEORY OF FREQUENCY-DISTRIBU- TIONS.1}

THREE brief but important notes on the theory of the law of error were communicated to the Royal Academy of Sciences at Stockholm last year by Mr. Charlier, director of the astronomical observatory at Lund. The first of these ("Ueber das Fehlergesetz") is a discussion on the lines, generally, laid down by Laplace. An "error" is supposed to be given by the sum of a large number of elementary errors, each with its own law of frequency; these laws need not be the same, but are subject to the condition that the frequency should not fall off with great rapidity on either side of the mode. On this condition, the law reached is the known expansion in terms of the normal function and its differentials, recently discussed in detail by Prof. Edgeworth (Camb. Phil. Trans., vol. xx.). In his second note ("Die zweite Form des Fehlergesetzes") Mr. Charlier discusses the complementary case, in which the condition stated does not hold, supposing, for instance, that each elementary error can only take the value zero or $a$, and that the probability of $a$ is very small. The normal function of the former series is now replaced by an auxiliary function of more complex form. These two laws are referred to as Type $\mathrm{A}$ and Type B. The third note ("Ueber die Darstellung willkürlicher Funktionen ") bears on the general mathematical method employed.

The present memoir, which is written in English, is a sequel to these purely mathematical notes, discussing the practical work of fitting such curves to given statistics and so forth. The method of fitting used throughout is Prof. Pearson's " method of moments," which has proved so widely applicable. The illustrations are numerous; for Type A, frequencies of stigmatic rays in Papaver, Johannsen's distributions of weight in beans, cephalic indices of Swedish recruits, and deaths from typhoid fever in groups of three successive days during an epidemic at Lund; for Type B; De Vries's statistics of numbers of petals in Ranunculus, and Johannsen's figures for sterility in barley. Davenport and Bullard's data for the numbers of glands in the fore-legs of swine are discussed under both heads. These illustrations are followed by a short section on the dissection of a compound curve by Pearson's method (Phil. Trans., I893). One or two possible cases of approximation are discussed, and an interesting suggestion made as to the employment of a graphic method to lighten the labour of solving the fundamental nonic. The text of the memoir is followed by some tables giving, inter alia, the third and fourth differentials of the normal function, and values of the auxiliary function for Type B.

There are several incidental points of interest; a proof of the empirically discovered rule that the difference between mean and median is one-third of the difference between mean and mode for Type $A$ deserves mention, and a suggestion as to an arithmetical check in calculating moments is worth consideration from the practical standpoint. If one may judge from a diagram (Fig. 5), curves of Type A may be bi-modal. Is this so? The point does not appear to receive special attention in the text. The statement on p. ${ }_{5} 5$ that "as a rule it may be advisable

1 "Researches into the Theory of Probability." By C. V. L. Charlier. Pp. 51. (Meddelanden från Lunds Astronomiska Observatorium, Serie ii. Nr. 4. Kongl. Fysiografiska Sällskapets Handlingar. Bd. 16.) (Lund,
1906.)

No. I9I 2, vol. 74] to take the class range smaller than the standard deviation" would seem to be rather incautious. Surely, as a rule, it should be not merely smaller, but a good deal smaller--say one-third of the standard deviation or less?

The memoir and its preceding notes must be commended to the attention of all who are interested in the theory of frequency distributions either from the mathematical or the statistical side.

G. U. Y.

\section{A PLEA FOR AN EXPEDITION TO}

\section{$M E L A N E S I A$}

DR. A. C. HADDON, F.R.S., recently brought before the research department of the Royal Geographical Society a plea for the investigation of biological and anthropological distributions in Melanesia. The Melanesian islands constitute a fairly well-marked biological province. Many of the islands are of large size, and there is reason to believe that some of these are vestiges of an ancient land-mass that probably became submerged in the Mesozoic period. The islands of Melanesia have yet to be studied from a geomorphological point of view, and their geology is extremely little known. Botanists would welcome a more ample knowledge of the flora of the district as a whole and of particular portions of it, and many problems of plant structure, distribution, and œcology require detailed investigation on the spot. The same remarks apply to zoologists. Botanists and zoologists alike would welcome an opportunity for extensive or intensive study of the systematic distributional or biological problems of plants and animals in Melanesia.

There are also many anthropological problems in Melanesia that require investigation in the immediate future, since the dying out or modification of arts, crafts, customs, and beliefs that is now taking place, and the shifting and mixing of populations, will soon render their solution difficult and even impossible. On the other hand, there are many districts never yet visited by a white man, and many islands of which science has no knowledge.

There is a certain amount of variation in the physical character of the people of these archipelagoes that requires local study for its explanation. A good deal is known in a general way about the arts and crafts of the Melanesians, but an investigation of the kind proposed would verify existing data, add an immense number of trustworthy facts, and localities could be ascertained of unlocated specimens in our museums, and the uses of doubtful objects could in many cases be discovered. By a combination of these two lines of inquiry, the physical and the cultural, the nature, origin, and distribution of the races and peoples of the West Pacific could be elucidated. Melanesia is peculiarly suitable for studying the stages of the transition from mother-right to father-right, and it would be important to discover the causes that have led to this transformation, and the steps that mark its progress. With this is associated the evolution of the family and the distribution and inheritance of property. Melanesia is also a favourable area for tracing the emergence of government. What are required at the present day are intensive studies of restricted areas, since it is only by careful regional study that the real meaning of institutions and their metamorphoses can be understood. The same applies equally to all the manifold beliefs and usages that are grouped under the term religion. The psychology of backward peoples has been greatly neglected, and the opportunity of a well-equipped expedition would do much to encourage students to undertake this research.

It is superfluous to extend this plea, as all ethnologists will agree that this work requires to be done, and that without delay. The presence of Government officials, missionaries, traders, and of returned indentured labourers tends rapidly to modify or destroy the old customs. Much has already disappeared in many places; we are yet in time in many others if we do not delay.

Dr. Haddon is convinced that the best means of accomplishing the end in view is to organise a prolonged expedition to the Pacific with the absolute control of a 